\title{
O discurso dos adolescentes sobre vida sexual na adolescência ${ }^{1}$
}

\section{Adolescents' discourse about sexual life in adolescente}

\author{
El discurso de los adolescentes sobre la vida sexual en la adolescencia
}

\author{
Roseli do Carmo', I sabel Cristina Pacheco Van der Sand"
}

\section{RESUMO}

Estudo qualitativo, descritivo, que objetiva conhecer o discurso dos adolescentes acerca de prática sexual segura ou não (com ou sem uso de métodos contraceptivos) no período da adolescência. Realizado em uma escola estadual de Panambi/RS, junto a 20 adolescentes de ambos os sexos, no primeiro semestre de 2006. Na coleta de dados utilizouse a entrevista semi-estruturada e na análise dos dados a proposta de análise de conteúdo de Bardin. Da análise emergiram dois temas: "Entre o considerar normal e o ainda não estar na hora certa: o discurso dos adolescentes sobre vida sexual na adolescência"; e, "Agora é a hora? - o que pensam os adolescentes sobre iniciar sua vida sexual nessa fase da vida". Do primeiro tema depreende-se que os adolescentes estão em busca de uma sexualidade que se pauta em relações éticas, que não está centrada na genitalidade, mas em aspectos afetivos. Do segundo, emerge que quanto ao início de atividade sexual na adolescência, os jovens, em sua maioria, se posicionam que ainda não é a "hora certa". Há, no entanto, o reconhecimento e a reivindicação do direito ao exercício à sexualidade, entendida em um sentido amplo, ou seja, associado ao afeto, ao amor e pautado em relações éticas.

Palavras chave: Adolescente; Sexualidade; Contracepção.

\section{ABSTRACT}

The present essay is a descriptive and qualitative study. It has the purpose of knowing the adolescents' discourse about the safe (or not safe) sexual practice (with or without contraceptive methods) in adolescence period. We realized open interviews with 20 students from both sexes, in the first semester of 2006, in a public school in Panambi City, (Rio Grande do Sul State). For data collection we used semi-structured interview and to analyze the data, we followed the content analysis purpose from Bardin. Then, two themes came out: "Between consider normal and not to be at the right time yet: the adolescents discourse about sexual life in the adolescence"; and "Is it the rigth time? - what the adolescents think about starting their sexual life in this period of life". From the first theme, we can infer that the adolescents are searching for a sexuality based in the ethical relations, not only focused in genitality, but in affectionate aspects. From the second theme, we can conclude that, about the beginning of sexual activity in the adolescence, the teenagers majority think that it is not the "right time" yet. However, there is the recognition and the claim of the right to the sexuality activity, which is understood in a major context, in other words, associated to the affect, love, and based in ethical relations.

\section{Key words: Adolescent; Sexuality;} Contraception.

\section{RESUMEN}

Estudio cualitativo y descriptivo, que objetiva conocer el discurso de los adolescentes acerca de la práctica sexual segura o no (con o sin uso de métodos contraceptivos) en el periodo de la adolescencia. Realizado en una escuela estadual de Panambi/RS, junto a 20 adolescentes de ambos sexos. En la recolección de los datos se utilizó la entrevista semi estructurada y en el análisis de los datos la propuesta de análisis del contenido de Bardin. Del análisis emergieron dos temas: "Entre e I considerar normal y el todavía no estar en el momento cierto: el discurso de los adolescentes sobre la vida sexual en la
1 Trabalho de Conclusão de Curso de Enfermagem da Universidade Regional do Noroeste do Estado do Rio Grande do Sul - Unijuí.

'Estudante, formanda do Curso de Enfermagem da Unijuí. II Professora orientadora, docente adjunta do Departamento de Ciências da Saúde da Unijuí. E-mail: isabelvan@gmail.com 
Carmo R, Van der Sand ICP. O discurso dos adolescentes sobre vida sexual na adolescência. Revista Eletrônica de Enfermagem [serial on line] 2007 Mai-Ago; 9(2): 417-431. Available from: URL: http://www.fen.ufg. br/revista/v9/n2/v9n2a10.htm

adolescencia"; y, "¿Ahora es la hora? - qué piensan los adolescentes sobre iniciar su vida sexual en esa fase de la vida". Del primer tema se concluye que los adolescentes están en busca de una sexualidad que se basa en relaciones éticas, que no está centrada en la genitalidad, sino en aspectos afectivos. Del segundo, surge que cuanto al inicio de la actividad sexual en la adolescencia, los

\section{NTRODUÇÃO}

Até 1960 , de acordo com IBGE, a taxa de fecundidade total, estimada para o Brasil, era ligeiramente superior a seis filhos por mulher $^{(1)}$. A fecundidade foi declinando ao longo dos anos, passando de 5,8 nascidos vivos para 2,5 entre 1970 e 1996(2). Já, em 1991, posicionava-se em 2,89 filhos por mulher e, em 2000, em 2,39, tudo isso a custa de transformações sociais, como um todo, e no seio da família brasileira, em particular ${ }^{(1)}$.

A velocidade do declínio acelerou-se entre 1978 e 1985, e a maior parte desta redução foi observada entre as mulheres em grupos etários centrais do período reprodutivo. Conseqüentemente, a contribuição proporcional da fecundidade entre as adolescentes à fecundidade total tem aumentado ao longo do tempo ${ }^{(2)}$.

Cabe destacar que o IBGE informa que a taxa de fecundidade entre mulheres jovens continuará incrementando-se até 2010 (em $2000,9,0 \%$, o que significa que de cada 100 mulheres de 15 a 19 anos, nove já haviam tido pelo menos um filho - e 10,3\%, em 2010). Os dados deste Instituto informam que em 2000, da fecundidade total experimentada ao longo do período fértil, $18,8 \%$ correspondiam às mulheres de 15 a 19 anos $^{(1)}$. jóvenes, en su mayor parte, se posicionan que todavía no es "el momento". Ahora bien, existe el reconocimiento y la reivindicación del derecho al ejercicio a la sexualidad, entendida en un sentido amplio, o sea, asociado al afecto, al amor y basado en relaciones éticas.

Palabras clave: Adolescente; Sexualidad; Anticoncepción.

Em estudo sobre o contexto sóciodemográfico das adolescentes brasileiras no ano $2000^{(3)}$ foi revelado que uma ampla parcela de jovens encontrava-se em situação de vulnerabilidade, apontando um contexto ainda mais preocupante para as adolescentes com filhos, as quais mesmo constituindo família apresentavam dependência e/ou vinculação com seu grupo familiar original ou do seu cônjuge. Eram, em maior proporção, responsáveis por domicílios e famílias; uma vez unidas apresentavam maior proporção de dissolução das uniões; se economicamente ativas apresentavam maiores proporções de população economicamente ativa não-ocupada; ostentavam maiores proporções de não freqüência escolar; estavam inseridas em domicílios com os menores níveis de rendimento per capita ${ }^{(3)}$.

Nas situações em que as estimativas puderam ser realizadas, foi constatado que as adolescentes de 10 a 14 anos com filhos estavam inseridas em contextos ainda mais adversos, segundo as variáveis analisadas, do que as adolescentes de 15 a 19 anos igualmente com filhos.

Considerando esses dados, é importante o questionamento realizado por Ramos ${ }^{(4)}$, acerca do fato de que, embora os jovens conheçam a necessidade de usar métodos de 
Carmo R, Van der Sand ICP. O discurso dos adolescentes sobre vida sexual na adolescência. Revista Eletrônica de Enfermagem [serial on line] 2007 Mai-Ago; 9(2): 417-431. Available from: URL: http://www.fen.ufg. br/revista/v9/n2/v9n2a10.htm

anticoncepção e, na sua maioria, estejam determinados a usá-los, continuam a ter relações sexuais não protegidas. Essa autora questiona se a acessibilidade é um fator importante e determinante deste tipo de comportamento, destacando que existem alguns condicionantes ao uso da contracepção que estão relacionados, entre outros fatores, com dificuldades individuais ao acesso à contracepção $^{(4)}$.

Os adolescentes que usam irregularmente a contracepção revelam atitudes negativas, tais como medo de interferência com o desempenho sexual e medo de que pareça haver premeditação do ato. Os jovens com baixo nível cognitivo estão menos motivados à contracepção, não conhecem a fisiologia básica da reprodução, como também não se conscientizaram sobre os riscos de não fazer anticoncepção $^{(4)}$

Como dificuldades institucionais ao acesso da contracepção, são apontadas: a falta de privacidade para o atendimento aos adolescentes, a grande carga de procedimentos administrativos nas instituições, o atendimento moroso e tardio, a pouca disponibilidade dos profissionais, os horários rígidos e inadequados às necessidades dessa clientela, as normas pouco flexíveis e culpabilizantes, o atendimento e instalações pouco motivantes, a falta de neutralidade dos profissionais na avaliação da problemática adolescente por conhecimento prévio da dinâmica familiar, a pouca articulação com outras redes de apoio aos adolescentes. Entre as dificuldades sócioculturais no acesso à contracepção destaca as comunidades rígidas e fechadas, o contexto cultural, religioso, os mitos e os tabus ${ }^{(4)}$.
Em contraposição a alguns desses condicionantes, cabe destacar que, em novembro de 2003, profissionais envolvidos na atenção a adolescentes reuniram-se para discutir aspectos da contracepção na adolescência, abarcando o descompasso entre a proposta ética e o respaldo legal ${ }^{(5)}$. Neste fórum, foi concluído que a privacidade é o direito que 0 adolescente possui, independentemente da idade, significando que se for de sua vontade deve ser atendido sozinho, em um espaço privado de consulta, inclusive durante o exame físico, onde são reconhecidas sua autonomia e individualidade.

Outro direito reconhecido, na mesma oportunidade, diz respeito à confidencialidade, que é reconhecida no Código de Ética Médica, pois a quebra do sigilo, também prevista nesse Código, deverá ser realizada com o conhecimento do adolescente, mesmo que sem sua anuência. Por fim, parece importante resgatar que nesse encontro foi reconhecido que o adolescente tem direito à educação sexual, ao acesso à informação sobre contracepção $^{(5)}$.

Em artigo acerca da educação sexual na escola, Saito e Leal $^{(6)}$ apontam que a literatura indica que adolescentes que receberam aulas de orientação sexual, usaram preservativos em maior escala na primeira relação e, ainda, que os jovens sempre apontam a escola como fonte de informação sobre sexualidade, valorizam não só esses conhecimentos como o local onde os receberam. Tal apontamento valida as recomendações do Fórum antes mencionadas. As autoras referem que "os horizontes da escola devem se ampliar cada vez mais, abrangendo conhecimentos sempre mais relevantes sobre adolescência e sexualidade, o 
Carmo R, Van der Sand ICP. O discurso dos adolescentes sobre vida sexual na adolescência. Revista Eletrônica de Enfermagem [serial on line] 2007 Mai-Ago; 9(2): 417-431. Available from: URL: http://www.fen.ufg.br/revista/v9/n2/v9n2a10.htm

que possibilitará o desenvolvimento de técnicas de abordagem ainda mais adequadas"(6).

O reconhecimento da criança como ser sexuado e a desvinculação do adolescente de estereótipos que o atrelam à liberação dos costumes, ao erotismo excessivo e à promiscuidade, são aspectos fundamentais no trabalho dos profissionais que se preocupam com a saúde sexual de crianças e adolescentes. A sexualidade, nesse contexto, não pode ser encarada como sinônimo de sexo ou atividade sexual, mas, sim, como parte inerente do processo de desenvolvimento da personalidade. A necessidade de que a orientação sexual não seja baseada no uso de preservativo ou de método contraceptivo, mas que tenha apoio no resgate do indivíduo enquanto sujeito de suas ações, favorecendo o desenvolvimento da cidadania e o compromisso ele mesmo e com o outro, é outro aspecto relevante dessa questão ${ }^{(6)}$. Saito e Leal ${ }^{(6)}$ resumem suas propostas de educação sexual mencionando que esta "deve conter liberdade, responsabilidade e compromisso, a informação funcionando como instrumento para que adolescentes de ambos os sexos possam ponderar decisões e fazer escolhas mais adequadas"(6).

Considerando este quadro teórico, desenvolvemos um estudo cujo tema diz respeito ao adolescente, à sexualidade e às práticas sexuais. Assim, esta investigação busca dar resposta a seguinte questão: O que pensam os adolescentes acerca da prática sexual, nessa fase da vida, com ou sem o uso de métodos contraceptivos?

A partir deste objeto, o objetivo do presente estudo é conhecer o discurso dos adolescentes acerca de prática sexual segura ou não (com ou sem uso de métodos contraceptivos) no período da adolescência.

Consideramos que de posse dos resultados desta investigação a Direção da Escola, local onde foi realizado o estudo, e demais interessados na saúde e na educação do adolescente poderão revisar suas práticas de atenção à saúde e pedagógicas junto a esse contingente populacional no que concerne ao tema sexualidade e práticas sexuais seguras.

\section{MÉTODO}

Tendo em vista a pergunta de pesquisa deste estudo, o desenho que nos pareceu mais adequado foi um estudo descritivo(7) de abordagem qualitativa ${ }^{(8)}$. O estudo foi realizado na Escola Estadual de Educação Básica Poncho Verde, de Panambi/Rio Grande do Sul, que no ano de 2005 contou com um total de 1.346 alunos. A escola atende estudantes da educação infantil, ensino fundamental e médio. Os sujeitos do estudo foram adolescentes do sexo masculino e feminino, na faixa etária dos 12 aos 18 anos incompletos, sendo incluídos somente os que aceitaram fazer parte do estudo. A escolha desta faixa etária fundamentou-se no Estatuto da Criança e do Adolescente - Lei Federal no 8.069/1990, que refere que adolescente é a pessoa de 12 a 18 anos incompleta.

Em vista da opção pela abordagem qualitativa, consideramos que a definição do tamanho da amostra poderia levar em conta a idéia de que a amostra ideal é aquela que reflete a totalidade em suas múltiplas dimensões, sendo suficiente o número que permite certa reincidência de informações ${ }^{(9)}$.

Tivemos a representação de sujeitos de ambos os gêneros, guardando a 
Carmo R, Van der Sand ICP. O discurso dos adolescentes sobre vida sexual na adolescência. Revista Eletrônica de Enfermagem [serial on line] 2007 Mai-Ago; 9(2): 417-431. Available from: URL: http://www.fen.ufg. br/revista/v9/n2/v9n2a10.htm

proporcionalidade de estudantes matriculados na Escola, ou seja, dez jovens do sexo masculino e dez do feminino.

Os dados foram coletados, no período de 21 de abril a 30 de maio de 2006, por meio da entrevista semi-estruturada ${ }^{(9)}$. Para isso, foi enviado ofício, por parte do curso de Enfermagem da Universidade Regional do Noroeste do Estado do Rio Grande do Sul (Unijuí), apresentando a pesquisadora (estudante) e solicitando permissão para a coleta de dados. A resposta da Direção da Escola foi positiva, indicando um professor vinculado a um componente curricular de maior afinidade ao tema do projeto de pesquisa. O professor designado, em sala de aula, comentou sobre o estudo, seu objetivo e acerca da entrevista, solicitando voluntários. Os sujeitos, e seus responsáveis legais, assinaram Termo de Consentimento Livre e Esclarecido para sua adesão ao processo de investigação.

As questões da entrevista semiestruturada disseram respeito ao pensamento do adolescente sobre vida sexual nesta fase e os cuidados a serem tomados pelo jovem que tem vida sexual ativa.

Para análise dos dados utilizamos a análise de conteúdo, criada por Bardin ${ }^{(10)}$. Esta técnica, entre suas funções, objetiva a “descoberta do que está por trás dos conteúdos manifestos, indo além das aparências do que sendo comunicado"(10). Abrange as fases de pré-análise, exploração do material, tratamento dos resultados obtidos e interpretação.

O estudo foi desenvolvido com base nos princípios éticos que regem uma pesquisa envolvendo seres humanos, segundo a
Resolução 196/96 do Ministério da Saúde ${ }^{(11)}$. O projeto de pesquisa foi encaminhado para o Comitê de Ética em Pesquisa da Unijuí para apreciação, tendo sido aprovado pelo Parecer Consubstanciado no 54/2006.

Para preservar o anonimato dos sujeitos foi utilizado um epíteto nominal (apelido) - o nome de pássaros, cuja escolha foi inspirada em trabalho de Caridade(12), quando ela compara a sexualidade do adolescente com o beija-flor - ao que chama de pulsão beija-flor.

\section{RESULTADOS E DISCUSSÃO}

Após leitura exaustiva das entrevistas e agrupamentos das falas por semelhança, emergiram no estudo duas categorias temáticas que dizem respeito ao discurso, ao pensamento e à ação dos adolescentes acerca da sexualidade, da vida sexual e do sexo seguro nesse período da vida. Tema I: Entre o considerar normal e o ainda não estar na hora certa: o discurso dos adolescentes sobre vida sexual na adolescência; Tema II: Agora é a hora? - o que pensam os adolescentes sobre iniciar sua vida sexual nessa fase.

\section{Tema I: Entre o considerar normal e o ainda não estar na hora certa: o discurso dos adolescentes sobre vida sexual na adolescência}

A sexualidade no ser humano possui longo desenvolvimento e tem seu início desde o nascimento, tratando-se, portanto, de uma organização que vai se estruturando desde a fase pré-genital até a genital propriamente dita, que é atingida com a maturidade. No entanto, cabe destacar que cada pessoa tem seu próprio desenvolvimento, com uma ordem particular e única ${ }^{(13)}$. 
Carmo R, Van der Sand ICP. O discurso dos adolescentes sobre vida sexual na adolescência. Revista Eletrônica de Enfermagem [serial on line] 2007 Mai-Ago; 9(2): 417-431. Available from: URL: http://www.fen.ufg. br/revista/v9/n2/v9n2a10.htm

Na adolescência, por volta de onze, doze anos - fase da puberdade, a sexualidade é auto-erótica, prevalecendo a masturbação. Porém, com o decorrer do tempo essa fase vai dando lugar para uma sexualidade homossexual, que depois pode se transformar em heterossexual. Assim, por volta dos quinze anos o adolescente começa a definir, de forma lenta, sua inclinação sexual, dando um novo aspecto às suas relações. Os jovens, sujeitos de nosso estudo, têm noção desse desenvolvimento, corroborando com as idéias antes mencionadas sobre a sexualidade no ser humano. Vejamos o que nos dizem dois adolescentes de idade de 18 e 14 anos, respectivamente:

Eu acho normal, depende do adolescente, tem muito isso, da preparação dele... Acho normal. O que é essa preparação que você se refere? Estar preparado psicologicamente e também fisicamente.... (Bem-te-vi, 18 anos, 30 ano, $\widehat{\jmath}$ ). Eu acho que depende do momento em que este adolescente está vivendo, pois se ele ta certo que é isto que ele deve fazer. O que estar certo na tua opinião? Estar certo é saber que você achou a pessoa que você sabe que gosta de você. Eu acho que sim. (Colibri, 14 anos, 8a série, +).

Seguindo as idéias de estudiosos sobre o tema ${ }^{(14)}$, parece-nos importante destacar que nesse desenvolvimento da sexualidade há um período em que o adolescente é bastante gregário, colocando a amizade com amigos do mesmo sexo, por exemplo, como uma forma de proteger-se do contato com o sexo oposto, que é muito desejado, mas, por outro lado, muito temido. Nessa fase as amizades são idealizadas $^{(14)}$ baseando-se a escolha do amigo em uma ou mais qualidades que o outro tem e que é admirada. Quando a adolescente J oão de Barro, como pode ser visto a seguir, refere que se deve aproveitar ao máximo a adolescência, saindo com amigos, indo a festas, praticando esportes, estudando, nos parece que esta proteção aí se coloca de uma forma velada. Vejamos ao que ela se refere:

Ah... Eu penso que cada um deve cuidar de sua vida, mas ah... Adolescência é uma parte da nossa vida que deve, devemos aproveitar o máximo. O que é aproveitar o máximo, para você? É sair com os amigos, ir nas festas, praticar esportes, estudar entre outros. (J oão de Barro, 13 anos, 8a série, ㅇ).

Nessa fala, além disso, é contundente a característica gregária do adolescente, a qual tem uma contribuição no processo de busca da identidade desse sujeito ${ }^{(14)}$, sendo a identidade sexual peça determinante em tal processo. Assim, as fantasias ou os contatos com indivíduos do mesmo sexo são comuns nessa fase, o que nada mais é do que uma etapa da evolução afetiva desse jovem.

A identidade de grupo permite que o adolescente vá em busca de sua autonomia, de forma "a negar a criança, que lembra a dependência dos pais - para continuar crescendo e atingir a maturidade"(14). Neste sentido, cabe lembrar que "o vínculo com o grupo proporciona a noção de força que vem dos pares e que para serem aceitos, os adolescentes assumem atitudes para as quais, muitas vezes, não estão preparados" (6).

Os dados de nosso estudo revelam, também, que o exercício da sexualidade contribui para o (re)conhecimento do corpo que se transforma na puberdade. As transformações físicas e psicológicas do púbere causam estranheza ao jovem e o processo de 
Carmo R, Van der Sand ICP. O discurso dos adolescentes sobre vida sexual na adolescência. Revista Eletrônica de Enfermagem [serial on line] 2007 Mai-Ago; 9(2): 417-431. Available from: URL: http://www.fen.ufg. br/revista/v9/n2/v9n2a10.htm

aceitação da imagem corporal é, em geral, fonte de angústia(15). Estudiosos alertam que tais transformações podem levar o adolescente “a um sentimento de rejeição do corpo atual que nem sempre condiz com o idealizado"(16).

Os jovens, sujeitos de nosso estudo, contribuem no sentido de esclarecer que na medida em que o exercício da sexualidade vai ocorrendo há uma aceitação dessas transformações, reduzindo sentimentos de vergonha, de constrangimento e de estranheza frente ao corpo e ao novo indivíduo que agora se institui.

Eu acho que é necessário, pois com a vida sexual você acaba conhecendo melhor seu corpo, você passa a não ter mais vergonha dele. (Acauã, 17 anos, 10 ano, ठ̊).

Ah, cada adolescente pensa de maneira diferente, por isso acho que quando chega uma certa idade todos querem conhecer coisas novas, também seu corpo, então é normal, pois isso é coisa de nossas vidas (Águia, 17 anos, 3ำ ano, ठ̋).

Os jovens entrevistados percebem que a adolescência é etapa da vida em que a maturação da sexualidade ocorre. Porém, talvez para se defenderem de idéias remanescentes em nossa cultura, pelas quais o exercício da sexualidade genital seria prerrogativa do indivíduo adulto, alguns afirmam que o adolescente não se sente culpado ou com medo de tal exercício, ao contrário do que trazem alguns estudos sobre o tema.

Esse tipo de idéia pode significar, por outro lado, um apelo à sociedade para que o exercício da sexualidade nessa faixa etária seja reconhecido como um direito do adolescente, cabendo ressaltar que a maioria, senão todos os entrevistados referem que há uma "hora certa", um sentir-se pronto para o exercício de tal direito e a necessidade da existência de amor entre o casal.

Nesse sentido, cabe destacar que "a evolução da sexualidade traz o exercício da genitalidade, colocando os adolescentes frente a frente com impulsos sexuais que deverão ser vivenciados" (6). Além disso, nos parece importante destacar que os educadores devem ser parceiros nessa trajetória para que no processo de educação sexual não sejam levados a imaginar o adolescente como um “conteúdo vazio a ser preenchido com os valores do orientador" (6).

É fundamental a compreensão de que professores e estudantes têm valores, histórias de vida propostas diferentes que compreendem, inclusive, o exercício da sexualidade ${ }^{(6)}$, o que pode ser observado no que os jovens dizem:

Acho extremamente normal, hoje em dia. Acho que as pessoas entram na vida sexual nessa faixa etária e também não se sentem culpadas ou com medo dessa atitude. Quando você sente que está na hora, este é o momento certo, bom se for com a pessoa certa. (Andorinha, 16 anos, 3ㅇano, ${ }^{\text {`) }}$.

Se o adolescente tiver um compromisso sério com uma pessoa e tiver preparado para isso não há problema. (Caburé, 16 anos, 3o ano, q).

Na minha opinião é normal, o certo seria com a pessoa que você ama realmente, mas muitas vezes isso não acontece. (Caneleiro, 18 anos, 3으 ano, ठึ).

Essas falas corroboram os resultados de outro estudo(17), em que, indiferente do 
Carmo R, Van der Sand ICP. O discurso dos adolescentes sobre vida sexual na adolescência. Revista Eletrônica de Enfermagem [serial on line] 2007 Mai-Ago; 9(2): 417-431. Available from: URL: http://www.fen.ufg. br/revista/v9/n2/v9n2a10.htm

gênero, a dimensão afetiva foi reconhecida como aspecto importante nas relações estabelecidas entre adolescentes. Nesse estudo, tanto meninos como meninas enfatizavam que tanto no namoro quanto no "ficar" é importante à existência da afetividade, o que vai ao encontro de nossos achados.

Quando meninos e meninas expressam a necessidade do amor, do afeto em suas relações e o direito do exercício da sexualidade quando "é chegada à hora", parece-nos que há, neste discurso, o desejo da superação da dupla moralidade social ainda vigente nos dias atuais, em que a iniciação sexual dos rapazes é estimulada e há a imposição da castidade para as moças até o casamento.

Com isso, nos parece que valem as reflexões sobre a sexualidade na adolescência, tecidas por Caridade(12), quando esta refere que a sexualidade na adolescência ganha a feição do contexto cultural em que o jovem está inserido. Nesse, o jovem se insere pela linguagem e pelos valores vigentes nessa época, não tendo, portanto, uma determinação biológica que mantenha uma verdade definitiva acerca do ato sexual. Nada, "está definitivamente estabelecido, tudo está permanentemente sujeito à revisão, pois cada sociedade inventa a sexualidade que pode inventar" (12).

Outra reflexão tecida pela mesma autora, é a comparação da sexualidade do adolescente com o beija-flor, ao que ela denomina pulsão beija-flor, referindo que o jovem é alguém que experimenta sua sexualidade na rapidez, na leveza e na diversidade, da mesma forma como faz esse pássaro, que busca o néctar em diversas flores "sem se deter em nenhuma especificamente, mas sem desrespeito algum, sem violação, sem estupros". Menciona, ainda, que "a prática do ficar, parece-me expressiva disso que chamo de pulsão beija-flor. [...] $\mathrm{Na}$ ética adolescente, ficar significa não ficar, não ter compromisso com amanhã, não criar vínculos definitivos. É pois não ficando quando ficam, que eles ensaiam, descobrem, experimentam, conhecem sensações, sem os 'pudores' de outras gerações" (12).

Ao analisarmos as expressões dos jovens estudados, consideramos que esses estão imersos na busca de uma sexualidade que passa por uma transição, afastando-se de paradigmas em que se ancorava a geração de seus pais e aproximando-se de algo que já está além do "ficar" sem ficar, de uma relação pautada em parâmetros mais éticos.

Parece-nos que suas falas vão ao encontro do pensamento de se não educamos os jovens no contexto da ética, estes poderão tornar-se meros e inescrupulosos consumidores de corpos ao invés de partilharem afeto e prazer. Em termos sexuais, ético seria aquilo que é bom e vivido em mão dupla, que atende ao interesse de ambos, que não violenta ninguém ${ }^{(12)}$.

Por outro lado, o pensamento e até mesmo o comportamento sexual do adolescente, ao dizer que agem sem culpa, pode ainda ter origem na série de desencontros em que é forjada a sexualidade nesta faixa etária. Assim, cabe destacar que a idéia corrente de que o jovem exerce sua sexualidade mais que os indivíduos de outras faixas etárias, nada mais é do que um engano produzido pelo adulto que, muitas vezes, insatisfeito com seu próprio desejo, idealiza o adolescente. Desta forma, o jovem muitas vezes se vê forçado a elaborar os desencontros 
Carmo R, Van der Sand ICP. O discurso dos adolescentes sobre vida sexual na adolescência. Revista Eletrônica de Enfermagem [serial on line] 2007 Mai-Ago; 9(2): 417-431. Available from: URL: http://www.fen.ufg. br/revista/v9/n2/v9n2a10.htm

que começa a experimentar com a incidência de seu desejo, significando que aquilo que se dá por meio do "ficar" elucidar a dificuldade que o jovem tem de sustentar uma relação ${ }^{(15)}$.

Diante dessa situação as atitudes do adolescente podem variar - recuando ou seguindo em frente. Assim, ao se negar a enfrentar seus desencontros ele poderá sucumbir à depressão ou mesmo tentar suicídio em casos extremos, ou ainda, desistir dos papéis sexuais pré-estabelecidos, aliviando-se do seu mal-estar por meio da dependência química, ou também, afastandose da realidade através de uma psicose ${ }^{(15)}$.

Possivelmente em virtude dos elementos culturais que estão a dar forma à sexualidade que podemos inventar, entre outros fatores, os adolescentes estudados enfatizam que o exercício da atividade sexual nesse período da vida deve ser acompanhado de uso de preservativo e/ou contraceptivos hormonais, como pode ser visto abaixo:

Desde que esteja consciente que é preciso usar preservativos e outros métodos anticonceptivos, acho normal. (Caracará, 13 anos, 8a série, + +).

Bom, eu penso que um adolescente ter vida sexual é uma coisa normal, no tanto que ele esteja assim prevenido, que use preservativo e saiba o que está fazendo. (Tesourão, 14 anos, 7a série, $\widehat{\jmath})$.

O exercício consciente da sexualidade, lançando mão do sexo seguro, parece indicar a apreensão, por parte dos adolescentes, das preocupações atuais em relação à prevenção de doenças sexualmente transmissíveis e da gestação na adolescência, pois ao lado de um declínio importante na fecundidade total no Brasil (mais de quatro filhos por mulher, na década de 1970, passando a 2,5 em 1996), entre as jovens de 15 a 19 anos esta tem aumentado ligeiramente e o aumento é ainda maior na faixa de dez a 14 anos $^{(1,18)}$. Em virtude deste quadro, muitas são as campanhas no sentido de reverter esta situação, o que parece estar mobilizando, pelo menos, alguns adolescentes.

Os dados de nosso estudo evidenciam que os jovens possuem um nível adequado de conhecimento acerca de sexo seguro, apesar da existência de algumas concepções ainda equivocadas e preconceituosas, como pode ser observado na fala que segue:

Ah, eu acho normal, desde que seja entre homem e mulher. (Melro, 16 anos 10 ano, ठ).

A fala acima revela a necessidade, já mencionada, de uma orientação aos adolescentes que seja pautada na ética, no respeito ao outro, em que haja superação de posições intolerantes e a convivência harmoniosa com a diversidade.

Neste tema percebemos, também, que a perda da virgindade ainda se coloca como marco importante para os jovens. Mas antes de tudo, possivelmente pelo tipo de orientação que recebem, seja no meio familiar como no escolar, e também pelo contexto cultural em que estão inseridos, suas preocupações estão voltadas para agravos oriundos da vida sexual ativa - especialmente a gravidez, seguida das doenças sexualmente transmissíveis (DSTs). Vejamos as falas que seguem:

Bom, no meu ponto de vista eu não acho legal um adolescente perder a virgindade muito cedo, pois a maioria transa sem camisinha, pegam doenças sexualmente transmissíveis e acabam engravidando suas parceiras, 
Carmo R, Van der Sand ICP. O discurso dos adolescentes sobre vida sexual na adolescência. Revista Eletrônica de Enfermagem [serial on line] 2007 Mai-Ago; 9(2): 417-431. Available from: URL: http://www.fen.ufg. br/revista/v9/n2/v9n2a10.htm

estragando a adolescência dos dois. (Martim Pescador, 17 anos 3으 ano, ठొ).

Acho muita irresponsabilidade da parte dos adolescentes, porque pode acontecer que engravidem e isso atrasaria os estudos e, muitas vezes, até param de estudar e deixam de ter um futuro melhor e de se formar até. E..., também corre o risco de doenças transmissíveis. (Mergulhão, 13 anos 7 o série, ㅇ).

Bom, acredito que esta é uma fase onde precisamos nos deter mais ao estudo, além, de eu acreditar que uma relação sexual possa ser somente estabelecida após ter casado. (Flamingo, 17 anos, 3o ano, ठึ).

Aqui nos parece importante trazer novamente as reflexões de Saito e Leal ${ }^{(5)}$, já apontadas na introdução deste estudo, quando destacam que a orientação sexual não deve se basear no uso de preservativo ou métodos de contracepção, mas que deve investir no resgate do indivíduo como sujeito de suas ações, o que irá contribuir no desenvolvimento da cidadania e do compromisso consigo mesmo e com o outro. Essa proposta não invalida terse sempre presente a anticoncepção como parte relevante das estratégias preventivas, pois os métodos anticoncepcionais devem ser desmistificados, com o reconhecimento do baixo risco das pílulas, da ineficácia do coito interrompido e da eficiência dos preservativos, também usados para proteger a vida, ou seja, na prevenção das DST/HIV/Aids ${ }^{(5)}$.

Por fim, depreendemos deste tema que grande parte dos adolescentes estão em busca de uma sexualidade que se pauta em relações éticas. A sexualidade não está centrada na genitalidade, mas nos aspectos afetivos das relações, no prazer do estar junto sem comprometer perspectivas de futuro, que acreditam centrar-se, especialmente, nas possibilidades oriundas do estudo.

\section{Tema II: Agora é a hora? - o que pensam os adolescentes sobre iniciar sua vida sexual nessa fase.}

No que diz respeito ao fato de iniciarem atividade sexual neste momento em que estão vivendo, os sujeitos desse estudo, em sua maioria, se posicionam que ainda não é a "hora certa". Cabe ressaltar que a literatura se posiciona afirmando não ter um momento exato, do tipo manual, pois esta, como já afirmamos no tema I, é uma questão muito pessoal, variando de indivíduo para indivíduo ${ }^{(13)}$.

Acho que não, lógico sou muito nova tanto para namoros sérios, quanto relações sexuais, acho que nem pensar nisso..., pensar quando estiver acabando os estudos para não prejudicar meu futuro com acidentes desse tipo. Que tipos de acidentes? Acidentes do tipo engravidar ou até mesmo causar uma doença sem cura ou com cura, mas muitos medicamentos que possam prejudicar e prejudicar minha saúde. E um filho agora com toda certeza não seria bom. (Mergulhão, 13 anos, 7a série, o).

Acho que transformaria muito minha vida, uma vez que acredito que o sexo é algo extremamente essencial na vida, mas não neste momento dela. (Flamingo, 17 anos, 3ㅇ ano, ô).

Cabe destacar o que é trazido por Caridade $^{(12)}$, quando esta assevera que o sexo está liberado em nossos dias, tendo saído da privacidade, da intimidade da casa para a rua, para as telas, para a luz do dia; havendo, 
Carmo R, Van der Sand ICP. O discurso dos adolescentes sobre vida sexual na adolescência. Revista Eletrônica de Enfermagem [serial on line] 2007 Mai-Ago; 9(2): 417-431. Available from: URL: http://www.fen.ufg.br/revista/v9/n2/v9n2a10.htm

portanto, desembaraçado-se dos direitos e deveres, dos laços, obrigações e direitos adquiridos. A sexualidade que é estimulada e insinuada, segundo a autora, é a do exibicionismo de corpos, do voyeurismo de contemplá-los e do fetichismo de consumi-los, levando ao exercício da "sexualidade vivida no corpo não na pessoa. Mais desempenho e sensação que sentimento. Mais uso do outro do que partilha. Mais quantidade que qualidade. Essa é a sexualidade que nossos adolescentes são estimulados a inventar"(12).

Os dados de nosso estudo, em parte, parecem ir ao encontro do que diz a referida autora e, por outro lado, também ir contra suas reflexões, pois os depoimentos antes apresentados evidenciam que os jovens estão à espera de um momento que percebam ser mais adequado para sua iniciação sexual, considerando que esta fase de suas vidas deve ser dedicada a outros interesses, tais como o estudo, o esporte, as amizades.

No entanto, como pode ser percebido na fala abaixo, há os que consideram ser esta a fase adequada para tal iniciação.

Eu acho normal, pois a sociedade evoluiu muito e hoje em dia os adolescentes cada vez mais cedo têm uma vida sexual ativa. (Urutau, 15 anos, 1 ㅇ ano, + ).

Talvez a evolução a qual se refira a estudante diga respeito à publicidade veiculada em torno da sexualidade antes mencionada, o que vem ocorrendo de forma contundente especialmente pelos meios de comunicação. Neste sentido, contribuem as reflexões que chamam atenção para o fato de que nos dias atuais não há como negar a influência da televisão nos lares de todas as camadas populacionais $^{(19)}$. Brasil, Mitsui e Alves(19) reforçam essa questão citando a tese de doutoramento de Waideman afirmando que "os meios de comunicação estimulam condutas comportamentais que privilegiam o erotismo, o culto ao corpo, o prazer pelo prazer físico, o sexo como artigo de consumo, ao mesmo tempo em que a sociedade como um todo ainda tem pouco a oferecer em termos de garantias físicas, psicológicas e sociais para que os adolescentes, homens e mulheres, possam com tranqüilidade usufruir da sua sexualidade" (19).

Preocupamo-nos, como os autores antes citados, com essa falta de garantia para nossos adolescentes, pois a iniciação sexual, muitas vezes influenciada por esses fatores, determina a emergência de situações com as quais o jovem, em geral, não tem condições efetivas de lidar - do ponto de vista social e psíquico, a exemplo de uma gravidez indesejada, de um sofrimento em virtude de um abandono por parte do companheiro/a, de um isolamento social e familiar, pois, muitas vezes, família e grupo social não estão preparados para acolher os desejos e as demandas desse adolescente que cresce.

Validando nossas impressões lançamos mão de estudo fenomenológico acerca da ambigüidade na tomada de decisão em comportamento sexual de meninas que vieram a engravidar ${ }^{(20)}$. Neste estudo foi apreendido que a informação sobre prevenção foi percebida, pelas jovens, como parcial e incompleta e a comunicação mostrou-se prejudicada por falta de confiança no interlocutor preferencial (no caso, a mãe). Além disso, os pesquisadores constataram que a rede de apoio, constituída por tias e amigas, mostrou-se falha em apresentar 
Carmo R, Van der Sand ICP. O discurso dos adolescentes sobre vida sexual na adolescência. Revista Eletrônica de Enfermagem [serial on line] 2007 Mai-Ago; 9(2): 417-431. Available from: URL: http://www.fen.ufg. br/revista/v9/n2/v9n2a10.htm

esclarecimentos ou reduzir incertezas. Além de despreparados, os interlocutores apresentaram dificuldades associadas à falta de informação e a não aceitação da sexualidade adolescente.

Embora na análise do tema I, alguns adolescentes tenham levantado a vivência de uma sexualidade mais afetiva, as expressões que seguem nos parecem revelar um certo descompromisso para com o outro.

O fato de se preocuparem com o uso de preservativo ou de anticoncepcionais nos parece um comportamento com duas faces uma, que protege ambos os parceiros de uma possível gravidez e/ou DST, e a outra que desvaloriza a necessidade de envolvimento emocional com o outro. Dentre as falas, nos chamam atenção as três que seguem, as quais parecem denotar essa nossa apreensão. Além disso, cabe ressaltar que esses depoimentos são de sujeitos do gênero masculino, postura que, possivelmente, ainda esteja ancorada em uma cultura em que ao homem é estimulado o sexo sem envolvimento afetivo.

É uma coisa normal, contanto que eu tome cuidado, usando preservativo na hora de uma relação sexual, isto não influenciará muito na minha vida. (Acauã, 17 anos, 10 ano, $̂$ ).

Eu penso que devo me prevenir bastante, usando camisinha, pois a pior coisa é você perder toda a juventude cuidando do seu filho ou filha em casa, ou comprando remédios para combater alguma doença sexualmente transmissível. (Martim Pescador, 17 anos, 3으 ano, ठ̂).

Eu acho bom, interessante desde que não me atrapalhe no andamento do meu trabalho e dos estudos. (Melro, 16 anos, 1ㅇ ano, $0^{\top}$ ).
Em contraposição, duas meninas assim se manifestam quanto à possibilidade de vida sexual nesta fase de suas vidas:

Eu não acho um problema, pois eu tenho um compromisso sério e me cuido. Como você se cuida? Eu tenho um parceiro sexual, só um né, e tomo anticoncepcional. (Caburé, 16 anos, $3^{\circ}$ ano, + +).

Acredito que se eu estiver ciente do que estou fazendo e estar com a pessoa certa (um namorado). $\mathrm{O} \ldots$, ah, não vai ter problema nenhum. (Estrelinha, 14 anos, 1으 ano, ㅇ).

As falas parecem revelar uma preocupação com envolvimento ético com o parceiro, com a satisfação emocional e não só o prazer pelo prazer ${ }^{(18)}$.

Ao lado desse compromisso com o outro, a fala de alguns meninos evidencia a noção de que o exercício da sexualidade deve ser pautado pela noção da responsabilidade, o que pode guiar o jovem em suas atitudes.

Eu penso que hoje em dia é muito normal, porque na minha idade eu já tenho mais responsabilidade, já sei os cuidados que se deve ter e os riscos. (Caneleiro, 18 anos, 3o ano, ô).

Importante se for inteligente e/ou consciente, uma burrada se for sem camisinha. (Rolinha, 17 anos 30 ano, ठึ).

Eu penso que é normal, faz parte de nossas vidas, chega uma certa idade que não tem como escapar da vida sexual, mas devemos ter, tomar os cuidados necessários. (Águia, 17 anos, 30 ano, ठึ).

Apesar das diferentes percepções de moças e rapazes sobre a sexualidade, os dados de nosso estudo parecem indicar que estamos, como já mencionado no tema I, numa época 
Carmo R, Van der Sand ICP. O discurso dos adolescentes sobre vida sexual na adolescência. Revista Eletrônica de Enfermagem [serial on line] 2007 Mai-Ago; 9(2): 417-431. Available from: URL: http://www.fen.ufg. br/revista/v9/n2/v9n2a10.htm

de transição para a conquista da igualdade entre os gêneros.

Percebemos que o acesso ao conhecimento e a possibilidade de prática da concepção pode contribuir para uma equiparação na responsabilidade entre homens e mulheres, porém há, ainda, a necessidade de estímulo ao diálogo entre parceiros para a efetivação de relações éticas. Este estímulo, a nosso ver, deve ser iniciado pelos adultos que interagem com esses jovens, os quais deveriam ser verdadeiros em suas relações, pois os mesmos servem de "espelho" para o comportamento dos jovens.

\section{CONSI DERAÇÕES FI NAIS}

Considerando o número cada vez maior de adolescentes iniciando a vida sexual e as conseqüências associadas à atividade sexual desprotegida, os profissionais de saúde e de educação necessitam estar preparados para abordagem deste tema durante $\mathrm{o}$ atendimento dos jovens. Constitui grande desafio a adequada orientação sexual, que implica em privilegiar a participação da família, da escola, da área de saúde e da sociedade em geral, nesse processo de educação.

Os resultados deste estudo indicam que o adolescente reconhece e reivindica seu direito de exercer a sexualidade nesta fase da vida, como possibilidade de iniciar a atividade sexual a partir do momento em que se considera pronto para tal. Este reconhecimento vem acompanhado do sentimento de que as relações devem estar associadas ao afeto e ao amor e que estas devem ser pautadas na ética e no respeito ao outro. Por outro lado, há no discurso, de alguns, preconceito com aquilo que consideram o diferente, especialmente acerca das relações homossexuais.

A perda da virgindade ainda é um marco importante para alguns adolescentes, porém as preocupações centrais estão referidas à prevenção de DST e gravidez indesejada. Ao mesmo tempo em que reconhecem que o uso de preservativos e de outros métodos de contracepção é necessário para a prevenção de tais agravos, aparece, no estudo, que este comportamento pode se aliar a certa desvalorização do envolvimento emocional com o outro.

O discurso masculino, em certa medida, parece estar ainda atrelado a noções culturais embasadas em questões de desigualdade entre os gêneros, em que ainda ao homem é estimulado o sexo sem envolvimento afetivo. No discurso feminino aparece, no entanto, preocupação com a satisfação emocional do casal e não só o prazer pelo prazer. É significativa a noção de que o exercício da sexualidade deve vir acompanhado da noção da responsabilidade, servindo de guia para o jovem em seus relacionamentos afetivosexuais.

Ressaltamos que para os adolescentes entrevistados, o estudo é sua maior preocupação, que tem um significado de futuro promissor. Esta representação faz com que se mostrem, pelo menos no discurso, preocupados com medidas preventivas em suas atividades sexuais. Este resultado talvez tenha emergido, nesta investigação, pelo fato de os dados terem sido coletados no interior de uma escola, local em que o "estudar" é o foco dos interesses e atenções.

Cabe aos profissionais da área da saúde dirigir esforços para que os adolescentes 
Carmo R, Van der Sand ICP. O discurso dos adolescentes sobre vida sexual na adolescência. Revista Eletrônica de Enfermagem [serial on line] 2007 Mai-Ago; 9(2): 417-431. Available from: URL: http://www.fen.ufg. br/revista/v9/n2/v9n2a10.htm

tenham, além do acesso aos métodos contraceptivos e de prevenção a doenças sexualmente transmissíveis, o direito de exercer sua sexualidade de forma responsável, consciente, tranqüila e ética, pois quando nos referimos à sexualidade devemos lembrar que esta tem em seu bojo questões relativas à identidade sexual, ao corpo, às expressões, aos afetos, à reprodução e à promoção da saúde sexual e reprodutiva.

Consideramos, do mesmo modo que outros estudiosos sobre o tema, que os serviços para adolescentes deveriam ter um forte componente educativo, contando com a participação dos próprios jovens, além de seus professores e pais. Assim, todos os envolvidos poderiam juntos, planejar a atenção relativa à vida sexual/reprodutiva/afetiva, proporcionando, ao adolescente, condições para refletir e decidir sobre o momento adequado para o início de sua vida sexual, sobre prevenção de agravos, de gravidez e para a busca da promoção de sua saúde e bem-estar.

\section{REFERÊNCI AS}

1. Oliveira JC, Albuquerque FRPC, Lins I. Projeção da população do Brasil por sexo e idade para o período 1980-2050 - revisão 2004. Metodologia e resultados. Rio de Janeiro, IBGE, 2004.

2. Grupta N, Leite IC. Tendências e determinantes da fecundidade entre adolescentes no nordeste do Brasil. Perspectivas internacionais de planejamento familiar. [cited 2007 mai 23] Número especial, 2001. p. 24-29. Anais... Available from: URL: http://guttmacher.org/pubs/journals/2702401P .pdf.
3. Correa H. Caracterização sociodemográfica das adolescentes brasileiras em 2000 segundo o status da fecundidade. Proceeding of the XIV Encontro Nacional de Estudos Populacionais, ABEP; 2004 set 20-24; Caxambu-Minas Gerais, Brasil, p.1-15.

4. Ramos R. Dificuldades no acesso à contracepção. Sexualidade \& planejamento familiar. [serial on line] 2001 Jan-Jun [cited 2005 out 13]; 29/30: 29-36 Available from: URL: http://www.apf.pt/revista/estudos.pdf

5. Saito MI, Leal MM. Aspectos éticos da contracepção na adolescência. Rev. Assoc. Med. Bras. [serial on line]. 2003 Set [cited 2007 Maio 19]; 49(3): 234-234. Available from:

URL:

http://www.scielo.br/pdf/ramb/v49n3/a14v49n 3.pdf

6. Saito MI, Leal MM. Educação sexual na escola. Pediatria (São Paulo). [serial on line]. 2000 [cited 2007 Maio 11]; 22(1): 44-48. Available from: URL: http://www.pediatriasaopaulo.usp. br/upload/p df/451.pdf

7. Minayo MCS, organizador. Pesquisa social: teoria, método e criatividade. 18a ed. Petrópolis(RJ): Editora Vozes; 2001.

8. Bodgan RC, Biklen, SK. Qualitative research for education: an introduction to theory and methods. 1 $1^{\mathrm{a}}$ ed. Boston/USA: Allyn and Bacon, 1982.

9. Minayo MCS. O desafio do conhecimento: pesquisa qualitativa em saúde. $1^{\underline{a}}$ ed. São Paulo: Hucitec/Rio de Janeiro: Abrasco, 1992.

10. Gomes, R. A análise de dados em pesquisa qualitativa. In: Minayo, MCS, organizadora. Pesquisa social: teoria, método e criatividade. 18a ed. Petrópolis(RJ): Editora Vozes, 2001. p. $67-80$. 
Carmo R, Van der Sand ICP. O discurso dos adolescentes sobre vida sexual na adolescência. Revista Eletrônica de Enfermagem [serial on line] 2007 Mai-Ago; 9(2): 417-431. Available from: URL: http://www.fen.ufg. br/revista/v9/n2/v9n2a10.htm

11. Brasil. Ministério da Saúde. Conselho Nacional de Saúde. Resolução 196 de 10 de outubro de 1996. Diretrizes e normas regulamentadoras da pesquisa envolvendo seres humanos. Brasília, 1996.

12. Caridade A. O adolescente e a sexualidade: crise na adolescência e no mundo. In: Ministério da Saúde (BR). Cadernos, juventude saúde e desenvolvimento. Brasília, DF: Ministério da Saúde. Secretaria de Políticas de Saúde. Área de Saúde do Adolescente e do Jovem. [serial on line]. 1999 Ago [cited 2006 J un 15]; 1(20): 206 -212. Available from: URL: http://www. bireme.br/bvs/adolec/P/cadernos/c apitulo/cap20/cap20.htm.

13. Signorelli EC. Sexualidade na adolescência. Companhia da Escola. [serial on line]. 2003 [cited 2005 Ago 30]; Available from: URL: http://www.ciadaescola.com. br/artigos/resulta do. asp? Categoria $=43 \&$ codigo $=62$.

14. Osório LC. Adolescente hoje. 2aㅡ ed., Porto Alegre(RS): Artes Médicas, 1992.

15. Dantas L, Feitosa P. Adolescência: uma complicada fase de transição. 200? [cited 2006 Jun 30] Available from: URL: http://www.dietanet.hpg. ig.com.br/nadolescen cia.htm.

16. Guzman CR, Cano MAT. O adolescente e a hospitalização. Revista Eletrônica de Enfermagem. [serial on line]. $2000 \mathrm{Jul}-\mathrm{Dez}$ [cited 2007 Mai 01] 02(02): Available from: URL:

http://www.fen.ufg. br/revista/revista2_2/ado hosp.htm.

17. Maheirie K, Umau LC, Orlandi R, Baierle RE. Oficinas sobre sexualidade com adolescentes: um relato de experiência. Psicologia em Estudo [serial on line]. 2005 SetDez [cited 2006 Jun 29] 10(3): 537-542.
Available

from:

URL:

http://www.scielo.br/pdf/pe/v10n3/v10n3a21. pdf.

18. Díaz J, Díaz M. Contracepção na adolescência. In: Ministério da Saúde(BR). Cadernos, juventude saúde e desenvolvimento. Brasília, DF: Ministério da Saúde. Secretaria de Políticas de Saúde. Área de Saúde do Adolescente e do Jovem, [serial on line]. 1999 Ago [cited 2006 Jun 15]; 1(24): 249-257. Available from: URL: http://www. bireme.br/bvs/adolec/P/cadernos/c apitulo/cap24/cap24.htm .

19. Brasil LS, Mitsui RE, Alves, RN. Mudanças no comportamento sexual do adolescente decorrentes do surgimento da SIDA no contexto social. Análise Psicológica. [serial on line]. 2000 [cited 2006 Jun 10]; 4(18): 465483. Available from: URL: http://www.scielo.oces. mctes.pt/pdf/aps/v18n 4/v18n4a04.pdf.

20. Dias ACGG, William B. Family talking about sexuality and pregnancy during adolescence: perceptions of pregnant adolescents. Psicol. Reflex. Crit. [serial on line]. 2000 [cited 2007 Mai 27]; 13(1): 109-125. Available from: URL: http://www.scielo.br/scielo.php?script=sci_artt ext\&pid=S0102$79722000000100013 \& \mathrm{lng}=\mathrm{es \& nrm}=\mathrm{iso}$.

Artigo recebido em 04.08.06

Aprovado para publicação em 27.08.07 